\title{
Comparative Efficacy of Low-Dose Oral Corticosteroids and Oral Mini Pulse Dexamethasone in Patients of Vitiligo
}

\author{
Khan MSI
}

\begin{abstract}
Introduction: Vitiligo is a common, acquired, discoloration of the skin with unknown etiology. There are numerous treatment options available for vitiligo, but none is universally effective. Systemic corticosteroids suppress immunity and lead to repigmentation but produce unacceptable side effects. Oral corticosteroid low dose treatment may be associated with fewer side effects than usual dose-treatment. Several data also showed that oral dexamethasone pulse treatment was effective in arresting progression of vitiligo yet fails to induce satisfactory repigmentation in the great majority of their patients.
\end{abstract}

Objectives: A clinical trial was carried out to compare the efficacy of low-dose oral corticosteroids and oral mini pulse dexamethasone in patients of vitiligo.

Materials and Methods: The study was conducted in the Department of Dermatology and Venereology, Combined Military Hospital $(\mathrm{CMH})$, Dhaka, Bangladesh during January 2013 to December 2013. Total sixty patients of vitiligo were enrolled and divided into group A and group B. Thirty of group $A$ patients were treated with oral prednisolone daily and thirty of group $B$ patients were treated with oral dexamethasone pulse therapy weekly.

Results: Out of sixty patients of vitiligo, maximum patients of both groups had progressive type of vitiligo. In Group-A, the duration of illness was an average of 10 months and in group-B, it was an average of 8.20 months. Single lesion was 15 (50\%) for Group-A and 14 (46.7\%) for Group-B. Multiple lesions were $15(50 \%)$ \& $16(53.6 \%)$ for Group-A and Group-B respectively. The study showed that improvement rate was highest for the lesions on the extremities, which was 18 (34.6\%) and lowest for back $03(5.8 \%)$. Out of all patients from Group-A, the mean size of the lesions were
$8.17 \mathrm{~cm}, 5.90 \mathrm{~cm}, 4.32 \mathrm{~cm}$ and $3.57 \mathrm{~cm}$ at $1 \mathrm{st}$ visit, 2nd visit, 3rd visit and 4th visit respectively. In Group-B, the mean sizes of the lesions were 7.50 $\mathrm{cm}, 4.92 \mathrm{~cm}, 3.00 \mathrm{~cm}$, and $4.75 \mathrm{~cm}$ at $1 \mathrm{st}$ visit, 2nd visit, 3rd visit and 4th visit respectively. Among the patients $27(90 \%)$ of group-A and $25(83.3 \%)$ of group B were improved after 16th week of treatment, slight response $4(13.3 \%)$ and $6(20 \%)$, moderate response $22(63.2 \%)$ and $18(59.4 \%)$ and marked response was $1(3.3 \%)$ and $1(3.3 \%)$ in group $A$ and group B respectively.

Conclusion: The study concluded that both the drugs, oral prednisolone and dexamethasone when used individually, were found to be equally effective in the treatment of vitiligo.

Key-words: Low-dose oral corticosteroids, oral mini pulse dexamethasone, vitiligo.

\section{Introduction}

Vitiligo is an acquired pigmentary anomaly of the skin manifested by depigmented white macules and patches, which may slowly enlarge with concurrent development of new lesions ${ }^{1}$. The cause is unknown but may involve genetic factors, autoimmunity, toxic metabolites and/or a higher vulnerability of melanocytes ${ }^{2-4}$. Vitiligo is associated with a number of autoimmune disorders, most common of which is hypothyroidism ${ }^{5}$. Abnormalities in both humoral and cell mediated immunity have been documented in vitiligo patients and they present a basis for using steroids in the treatment of vitiligo ${ }^{6}$. The course of vitiligo is highly variable, but rapid onset followed by a period of stability or slow progression is most characteristic $^{7}$. There are numerous treatment options available for vitiligo, but none is universally effective. Even among patients who respond to treatment there is high potential for relapse. So the search for special technique of therapeutic modalities is a continued effort ${ }^{1,3,5}$. Most therapies are intended

Lt Col Md Shirajul Islam Khan, MBBS, DDV, MCPS, FCPS, Classified Spl in Dermatology \& Venereology, CMH Ghatail. 
to restore pigment to the skin. All approaches have advantage and disadvantages; and none is appropriate for every patient with vitiligo ${ }^{5}$. Systemic corticosteroids suppress immunity, may arrest the progression of vitiligo and lead to repigmentation. Systemic steroids may also produce unacceptable side effects ${ }^{5,7}$. Few studies have been published regarding treatment modalities of vitiligo and these studies have shown inconsistent results regarding the efficacy of oral corticosteroids in inducing repigmentation and arresting progression of vitiligo. Oral corticosteroid pulse therapy has provided inconsistent results regarding the efficacy in the treatment of patients with vitiligo in some studies. Oral corticosteroid low dose treatment may be associated with less severe and fewer side effects than usual dose-treatment. Some studies showed that low-dose oral corticosteroids were effective without serious side-effects in preventing the progression and inducing repigmentation of actively spreading vitiligo. Several data showed that oral dexamethasone pulse treatment was effective in arresting progression of vitiligo yet fails to induce satisfactory repigmentation in the great majority of the patient. To minimize the side effects associated with corticosteroids in daily dose, the clinical efficacy of low-dose oral corticosteroids were assessed in vitiligo patients and compared with the approach using oral mini pulse dexamethasone in vitiligo patients.

\section{Methods and Materials}

A clinical trial was carried out to assess the efficacy of low-dose oral corticosteroids and oral mini pulse dexamethasone in patients of vitiligo. The study was carried out in the outpatient department of Dermatology and Venereology, Combined Military Hospital, Dhaka Cantonment, Dhaka. The duration of the study was from January 2013 to December 2013 and patients of vitiligo were the study population.

Sampling technique was convenient type of purposive sampling and total sixty patients of vitiligo were enrolled and divided into group $A$ and group $B$. Thirty of group A patients were treated by oral prednisolone and thirty of group B patients were treated by dexamethasone. The group $A$ patients were given daily doses of oral prednisolone (0.3 $\mathrm{mg} / \mathrm{kg}$ body weight) initially for 2 months; the dosage were reduced to half of the initial dose for the third month and were halved again for the fourth month. The patients of group $B$ were given $5 \mathrm{mg}$ dexamethasone as a single oral dose after breakfast on 2 consecutive days per week (10 mg/week) for 16 weeks. The effects of treatment were evaluated 4 weekly.

Prior to the commencement of this study, the aims and objectives of the study along with its procedure, alternative methods, risks and benefits of this study were explained to the patients in easily understandable local language and then informed written consent were taken from each patient. It was assured that all information and records were kept confidential. The patients were explained that they have the right to refuse or accept to participate in the study and they will not receive financial benefit from this study. Data were collected by face to face interview and were recorded in a questionnaire. Information was collected by taking medical history and clinical examination. Type of vitiligo whether progressive or stable were determined by history and physical examination. The disease were considered stable if no new lesion had appeared and preexisting lesion did not enlarge during last six months. Extent of vitiligo was assessed by counting the number and measuring the size of lesion. Baseline laboratory investigations included complete blood counts, serum urea, serum creatinine and electrolytes, plasma glucose fasting and 2 hours after breakfast, liver function tests and serum cortisol levels. All the patients were weighed before starting of treatment. Wood's lamp examinations of lesions were done to confirm the clinical diagnosis. In the first and fourth week of therapy plasma cortisol levels were determined in all patients.

The clinical response was evaluated at 4 weekly intervals for 12 weeks after completion of therapy and clinical comparison were done with baseline. Efficacy parameters included arrest of progression and percentage of repigmentation. Progression were said to be arrested if no lesion appeared or pre-existing lesions did not enlarge during last one month. By measuring the size of the lesion and a visual comparison of the baseline of the patient estimated the percentage of repigmentation. Repigmentaton were considered excellent (>75\%), marked (51\% to $75 \%)$, moderate $(26 \%$ to $50 \%)$ and slight $(25 \%$ or less). Data analysis was performed by 
Statistical Package for Social Science (SPSS), version-12. Statistical analysis was done and level of significance was measured by using appropriate procedures like chi square test $\left(\mathrm{X}^{2}\right)$ and t-test, where applicable. Level of significance ( $p$ value) was set at 0.05 and confidence level at $95 \%$.

\section{Results}

A clinical trial was carried out to compare the efficacy of low-dose oral corticosteroids and oral mini pulse dexamethasone in patients of vitiligo. Thirty of group A patients were treated by oral prednisolone daily and thirty of group B patients were treated by oral dexamethasone pulse therapy weekly.

The Table-I shows age distribution of two groups; for Group- A, $\leq 15$ years was $08(26.7 \%)$ and $>15$ years was $22(73.3 \%)$. For Group- B, $\leq 15$ years was $07(23.3 \%)$ and $>15$ years was $23(76.7 \%)$. $X^{2}$ value $=0.089$. $d f=1 . P=0.766$. The table shows that there was no statistically significant difference in two groups (>0.05).

Table-I: Distribution of age among study groups (with $\mathrm{X}^{2}$ test significance).

\begin{tabular}{|l|c|c|c|c|c|c|}
\hline \multirow{2}{*}{$\begin{array}{c}\text { Age in } \\
\text { groups }\end{array}$} & \multicolumn{4}{|c|}{ Study groups } & \multicolumn{2}{c|}{ Total } \\
\cline { 2 - 7 } & \multicolumn{2}{|c|}{ GROUP A } & \multicolumn{2}{c|}{ GROUP B } & \multicolumn{1}{c|}{} \\
\cline { 2 - 7 } & $\mathrm{n}$ & $\%$ & $\mathrm{n}$ & $\%$ & $\mathrm{n}$ & $\%$ \\
\hline$\leq 15$ Years & 08 & 26.7 & 07 & 23.3 & 15 & 25.0 \\
\hline$>15$ Years & 22 & 73.3 & 23 & 76.7 & 45 & 75.0 \\
\hline Total & 30 & 100.0 & 30 & 100.0 & 60 & 100.0 \\
\hline $\mathrm{X}^{2}$ value $=0.089 . \mathrm{df}=1 . \mathrm{P}=0.766$. & Not Significant $(>0.05)$ \\
\hline
\end{tabular}

Table-II shows that maximum patients of both groups had progressive type vitiligo. Only $13.3 \%$ and $10 \%$ respondents of Group-A and Group- B gave the history of stable vitiligo respectively. No statistical significant difference was observed between two groups ( $p$ value $=0.688)$.

Table-II: Distribution of study groups by history of progression $(n=60)$.

\begin{tabular}{|c|c|c|c|c|c|c|c|}
\hline \multirow{3}{*}{ History } & \multicolumn{4}{|c|}{ Study groups } & \multirow{2}{*}{\multicolumn{2}{|c|}{ Total }} & \multirow{3}{*}{ Significance } \\
\hline & \multicolumn{2}{|c|}{ GROUP A } & \multicolumn{2}{|c|}{ GROUP B } & & & \\
\hline & $\mathrm{n}$ & $\%$ & $\mathrm{n}$ & $\%$ & $\mathrm{n}$ & $\%$ & \\
\hline Stable & 04 & 13.3 & 03 & 10.0 & 07 & 11.7 & $X^{2}=0.162$ \\
\hline Progressive & 26 & 86.7 & 27 & 90.0 & 53 & 88.3 & $P=0.688$ \\
\hline Total & 30 & 100.0 & 30 & 100.0 & 60 & 100.0 & NS \\
\hline
\end{tabular}

Table-III shows that out of all patients of Group-A, the duration of illness ranging from 7 months to 36 months, with an average of 10 months. In group-B, the duration of illness ranging from 7 months to 24 months, with an average of 8.20 months. No significant difference was observed $(p$ value $=0.316)$.

Table-IIl: Distribution of study groups by duration of illness $(n=60)$.

\begin{tabular}{|l|c|c|c|c|c|l|}
\begin{tabular}{|l|c|c|c|c|} 
Duration \\
Of Illness \\
(Months)
\end{tabular} & $\mathbf{n}$ & Mean & $\mathbf{\pm}$ SD & Median & Range & Sign \\
\hline GROUP A & 30 & 10.00 & 7.24 & 08 & $7-36$ & $\mathrm{t}=1.010$ \\
\hline GROUP B & 30 & 8.20 & 6.54 & 06 & $7-24$ & $\mathrm{P}=0.316$ \\
\hline TOTAL & 60 & 9.10 & 6.90 & 06 & $7-36$ & NS \\
\hline
\end{tabular}

The table-IV shows that single lesion was 15 (50\%) in Group-A and $14(46.7 \%)$ in Group-B. Multiple lesions were $15(50 \%)$ and 16 (53.6\%) in Group-A and Group-B respectively. No significant difference was observed. ( $p$ value $=0.796$ ).

Table-IV: Distribution of study groups by number of lesion $(n=60)$.

\begin{tabular}{|c|c|c|c|c|c|c|}
\hline \multirow{3}{*}{$\begin{array}{l}\text { Number of } \\
\text { lesion }\end{array}$} & \multicolumn{4}{|c|}{ Study groups } & \multirow{2}{*}{\multicolumn{2}{|c|}{ Total }} \\
\hline & \multicolumn{2}{|c|}{ GROUP A } & \multicolumn{2}{|c|}{ GROUP B } & & \\
\hline & $\mathrm{n}$ & $\%$ & $\mathrm{n}$ & $\%$ & $\mathrm{n}$ & $\%$ \\
\hline Single & 15 & 50.0 & 14 & 46.7 & 29 & 48.3 \\
\hline Multiple & 15 & 50.0 & 16 & 53.3 & 31 & 51.7 \\
\hline Total & 30 & 100.0 & 30 & 100.0 & 60 & 100.0 \\
\hline
\end{tabular}

Table- $V$ shows that improvement rate was highest for the lesions on the extremities, which is 18 $(34.6 \%)$ and lowest for back 03 (5.8\%). Improvement rate of face with ear and neck was 17 $(32.7 \%)$; chest $10(19.2 \%)$ and abdomen was 04 (7.7\%). No improvement was found of lesions on the face and abdomen, which was $5(62.5 \%)$ and 3 $(37.5 \%)$ respectively. No statistical significant difference was observed between two groups. $\mathrm{P}$ value $=0.070(>0.05)$.

Table-V: Distribution of recovery pattern among site of lesion $(n=60)$.

\begin{tabular}{|l|c|c|c|c|c|c|}
\hline \multirow{2}{*}{ Site of lesion } & \multicolumn{4}{|c|}{ Recovery pattern } & \multicolumn{2}{|c|}{ Total } \\
\cline { 2 - 6 } & IMPROVED & NOT IMPROVED & $\mathrm{n}$ & $\%$ \\
\cline { 2 - 6 } & $\mathrm{n}$ & $\%$ & $\mathrm{n}$ & $\%$ & $\mathrm{n}$ & $\%$ \\
\hline Extremities & 18 & 34.6 & 00 & 0.0 & 18 & 30.0 \\
\hline Face with ear and neck & 17 & 32.7 & 05 & 62.5 & 22 & 36.7 \\
\hline Chest & 10 & 19.2 & 00 & 0.0 & 10 & 16.6 \\
\hline Abdomen & 04 & 7.7 & 03 & 37.5 & 07 & 11.7 \\
\hline Back & 03 & 5.8 & 00 & 0.0 & 03 & 5.0 \\
\hline Total & 52 & 100.0 & 08 & 100.0 & 60 & 100.0 \\
\hline \multicolumn{7}{|c|}{$\mathrm{X}^{2}$ value $=8.670 . \mathrm{df}=4 . \mathrm{P}=0.070$. Not Significant $\left.>0.05\right)$} \\
\hline
\end{tabular}


Table-VI shows that out of all patients from Group-A, the mean size of the lesions were $8.17 \mathrm{~cm}, 5.90 \mathrm{~cm}$, $4.32 \mathrm{~cm}$, and $3.57 \mathrm{~cm}$ at $1 \mathrm{st}$ visit, 2nd visit, 3rd visit and 4 th visit respectively. In Group- $B$, the mean size of the lesions was $7.50 \mathrm{~cm}, 4.92 \mathrm{~cm}, 3.00 \mathrm{~cm}$, and $4.75 \mathrm{~cm}$ at 1 st visit, 2nd visit, 3rd visit and 4th visit respectively. No statistical significant difference is observed between two groups.

Table-Vl: Distribution of clinical responses among the study groups $(n=60)$.

\begin{tabular}{|c|c|c|c|c|c|c|}
\hline $\begin{array}{l}\text { Size of lesion } \\
\quad(\mathrm{cm})\end{array}$ & $\begin{array}{l}\text { Study } \\
\text { groups }\end{array}$ & Mean & \pm SD & Median & Range & Significance \\
\hline \multirow{2}{*}{$\begin{array}{c}\text { Before Treatment } \\
\text { (1st Visit) }\end{array}$} & GROUP A & 8.17 & 3.11 & 08 & $3-15$ & \multirow{2}{*}{$\begin{array}{c}\mathrm{t}=0.779 \\
\mathrm{P}=0.439 \\
\text { NS }\end{array}$} \\
\hline & GROUP B & 7.50 & 3.51 & 07 & $1-20$ & \\
\hline \multirow{2}{*}{$\begin{array}{c}\text { After Treatment / } \\
2^{\text {nd }} \text { Visit at } 4^{\text {th }} \text { Week }\end{array}$} & GROUP A & 5.90 & 3.78 & 06 & $0-14$ & \multirow{2}{*}{$\begin{array}{c}\mathrm{t}=0.104 \\
\mathrm{P}=0.918 \\
\text { NS }\end{array}$} \\
\hline & GROUP B & 4.92 & 4.55 & 05 & $0-18$ & \\
\hline \multirow{2}{*}{$\begin{array}{c}\text { After Treatment } / \\
3^{\text {rd }} \text { Visit at } 8^{\text {th }} \text { Week }\end{array}$} & GROUP A & 4.32 & 4.34 & 05 & $0-12$ & \multirow{2}{*}{$\begin{array}{l}t=0.104 \\
P=0.918 \\
\quad \text { NS }\end{array}$} \\
\hline & GROUP B & 3.00 & 5.52 & 00 & $0-18$ & \\
\hline \multirow{2}{*}{$\begin{array}{c}\text { After Treatment / } \\
4^{\text {th }} \text { Visit at } 12^{\text {th }} \text { Week }\end{array}$} & GROUP A & 3.57 & 5.03 & 00 & $0-12$ & \multirow{2}{*}{$\begin{array}{c}\mathrm{t}=0.104 \\
\mathrm{P}=0.918 \\
\text { NS }\end{array}$} \\
\hline & GROUP B & 4.75 & 7.45 & 8.50 & $0-18$ & \\
\hline
\end{tabular}

Table-VII shows that among the patients of group-A \& B, $27(90 \%)$ and $25(83.3 \%)$ were improved respectively. The numbers of failure were $03(10 \%)$ and $05(16.7 \%)$ for Group-A and Group-B respectively. No statistical significant difference was observed between the two groups. $P$ value $=0.448$ $(>0.05)$.

Table-VII: Distribution of recovery rate among the study groups $(n=60)$.

\begin{tabular}{|l|c|c|c|c|c|c|}
\hline \multirow{2}{*}{ Recovery Rate } & \multicolumn{4}{|c|}{ Study groups } & \multicolumn{2}{|c|}{ Total } \\
\cline { 2 - 6 } & \multicolumn{2}{|c|}{ GROUP A } & \multicolumn{2}{|c|}{ GROUP B } & \multicolumn{2}{|c}{} \\
\cline { 2 - 6 } & $\mathrm{n}$ & $\%$ & $\mathrm{n}$ & $\%$ & $\mathrm{n}$ & $\%$ \\
\hline Improved & 27 & 90.0 & 25 & 83.3 & 32 & 86.7 \\
\hline Not improved & 03 & 10.0 & 05 & 16.7 & 28 & 13.3 \\
\hline Total & 30 & 100.0 & 30 & 100.0 & 60 & 100.0 \\
\hline $\mathrm{X}^{2}$ value $=0.577$. & $\mathrm{df}=1 . \mathrm{P}=0.448$. & Not Significant $(>0.05)$ \\
\hline
\end{tabular}

Table-VIII shows that after 16th week of treatment, slight response $4(13.3 \%)$ and $6(20 \%)$, moderate response $22(63.2 \%)$ and $18(59.4 \%)$ and marked response was $1(3.3 \%)$ and $1(3.3 \%)$ in group $A$ and group B respectively.

Table-VIII: Comparison of repigmentation in two groups.

\begin{tabular}{|l|c|c|c|c|c|c|}
\hline & \multicolumn{2}{|c|}{$\begin{array}{c}\text { Group A } \\
\text { (n=30) }\end{array}$} & \multicolumn{2}{c|}{$\begin{array}{c}\text { Group B } \\
\text { (n=30) }\end{array}$} & $\begin{array}{c}\text { Chi } \\
\text { value }\end{array}$ & $\begin{array}{c}\text { p } \\
\text { value }\end{array}$ \\
\hline & $\mathrm{n}$ & $\%$ & $\mathrm{n}$ & $\%$ & & \\
\cline { 1 - 5 } Slight (25\% or less) & 4 & 13.3 & 6 & 20.0 & \multirow{3}{*}{0.867} \\
\cline { 1 - 5 } Moderate (26\% to 50\%) & 22 & 63.2 & 18 & 59.4 & \multirow{2}{*}{0.648} \\
ns \\
Marked (51\% to 75\%) & 1 & 3.3 & 1 & 3.3 & & \\
\cline { 1 - 4 } Excellent response (>75\%) & 0 & 0 & 0 & 0 & & \\
\hline
\end{tabular}

\section{Discussion}

In this study, thirty of group A patients were treated with oral prednisolone daily and thirty of group B patients were treated with oral dexamethasone pulse therapy weekly. The findings of this study in respect to age, duration of the disease and disease progression, were similar with study findings of Habib et al and Radakovic-Fijan et $a^{8,9}$. Habib et al conducted a study with thirty patients with vitiligo. The mean age was 32.3 years (range, 21-51 years, standard deviation $=7.68$ ), and the mean disease duration was 3.6 years (range, $0.5-16$ years, standard deviation $=3.6$ ). The disease was stable in $9(30 \%)$ patients and progressive in $21(70 \%)$ patients $^{8}$. Radakovic-Fijan et al conducted a study where twenty-nine patients with vitiligo were included and of these, 25 had progressive and 4 had stable disease ${ }^{9}$.

On the basis of improvement, my study findings were consistent with Habib et al, Radakovic-Fijan et $\mathrm{al}$ and $\mathrm{Kim}$ et $\mathrm{al}^{8-10}$. The patients of Habib et al were given weekly pulses of dexamethasone consisted of $10 \mathrm{mg}$ on 2 consecutive days every week followed by 5 days off treatment for a maximum of 24 weeks and showed in their study that after a mean treatment period of $16+4$ weeks, progression was arrested in $18(85.7 \%)$ out of 21 patients with progressive vitiligo, while in the remaining $3(14.3 \%)$ patients; the progression of disease was not arrested. Repigmentation was noted in 14 (46.6\%) patients out of 30 patients at the end of 24 weeks. Out of these 14 patients, $13(92.9 \%)$ had progressive disease and one $(7.1 \%)$ had stable disease. It was found that the response of patients with progressive disease was significantly better $(p<0.05)$ as compared to stable disease in terms of repigmentation. Out of 14 patients showing repigmentation $11(78.6 \%)$ had generalized disease and $3(21.4 \%)$ had acrofacial disease. It was observed that the response was not significantly different $(P>0.05)$ in these two groups of patients. Out of the total 14 patients with repigmentation, 10 $(71.43 \%)$ patients had slight, $3(21.43 \%)$ patients had moderate repigmentation and one (7.14\%) patient had marked repigmentation. None had excellent repigmentation. The only patient showing marked repigmentation had stable disease at the beginning of the study. No response was observed in the remaining $16(53.3 \%)$ patients. They concluded that oral corticosteroid pulse therapy is an 
effective treatment modality to arrest progressive vitiligo but is only moderately effective in inducing satisfactory repigmentation ${ }^{8}$.

Radakovic-Fijan et al evaluated clinical response in monthly intervals. The patients were given weekly pulses of $10 \mathrm{mg}$ dexamethasone each on 2 consecutive days followed by 5 days off treatment for a maximum period of 24 weeks. After a mean treatment period of $18.2+/-5.2$ weeks, the disease activity was arrested in 22 out of 25 patients $(88 \%)$ who had active vitiligo before the study. Marked repigmentation occurred in 2 patients $(6.9 \%)$ and moderate or slight repigmentation in 3 patients $(10.3 \%)$ each. No response was noted in 21 patients (72.4\%). They concluded that oral dexamethasone pulse treatment is effective in arresting progression of vitiligo yet fails to induce satisfactory repigmentation in the great majority of their patient cohort ${ }^{9}$.

Kim et al evaluated eighty-one patients with vitiligo. The patients took daily low doses of oral prednisolone $(0.3 \mathrm{mg} / \mathrm{kg}$ body weight) initially for 2 months; the dosage was then reduced to half of the initial dose for the third month and was halved again for the fourth and final month. Arrested progression of vitiligo and repigmentation were noted in $87.7 \%$ and $70.4 \%$ of patients respectively. Patient age of 15 years or under and duration of disease of 2 years or less showed increased repigmentation with statistical significance. They concluded that low dose oral corticosteroids are effective in preventing the progression and inducing repigmentation of actively spreading vitiligo ${ }^{10}$.

\section{Conclusion}

Both the drugs, oral prednisolone and dexamethasone when taken orally individually, found to be equally effective in the treatment of vitiligo, but oral prednisolone was found to be superior in efficacy. Further multicenter, randomized, doubleblind study should be conducted with large sample size.

\section{References}

1. Halder RM, Taliaferro SJ. Vitiligo. Wolff $K$, Goldsmith LA, Katz SI, Gilchrest BA, Paller AS and Leffell DJ. Fitzpatrick's Dermatology in General Medicine. New York: The McGraw- Hill Companies; 2008. p.616-618.

2. Westerhof W. Vitiligo management update. Skin Therapy Lett 2000; 5(6):1-2,5.

3. Bleehen SS. Disorders of skin color. In: Champion RH, Burton JL, Burn DA, Breathnach SM eds. Rook/Wikinson/ Ebling textbook of Dermatology. London Blackwell Science 1998; 1753-1815.

4. Kovacs SO. Vitiligo. J Am Acad Dermatol 1998; 38: 647-66.

5. Njoo MD, Westerhof W. Vitiligo. Pathogenesis and treatment. Am J Clin Dermatol 2001; 2(3): 167-8.

6. Handa S, Pandhi R, Kaur I. Vitiligo: a retrospective comparative analysis of treatment modalities in 500 patients. J Dermatol 2001; 28: 461-6.

7. Imamura S, Tagami H. Treatment of vitiligo with oral corticosteroids. Dermatol 1976; 153(3): 179-85.

8. Habib A, Sheikh ZI, Khan QD, Rahman SB. Efficacy and safety of oral dexamethasone pulse treatment for vitiligo. Pakistan Armed Forces Medical Journal 2006 June; 2:1-6

9. Radakovic-Fijan S, Furnsinn-Friedl AM, Honigsmann $\mathrm{H}$, Tanew A. Oral dexamethasone pulse treatment for vitiligo. J Am Acad Dermatol 2001; 44(5): 814-7.

10. Kim SM, Lee HS, Hann SK. The efficacy of low-dose oral corticosteroids in the treatment of vitiligo patients. Int J Dermatol. 1999; 38(7):546-50. 